\title{
Current Opinion in Gynecology and Obstetrics The Effect of Ethnicity on Preterm Birth and its Influence on the Risk Factors for Prematurity
}

\author{
P Bachkangi ${ }^{1}$, AH Taylor ${ }^{2}$ and JC Konje ${ }^{3, *}$ \\ ${ }^{1}$ Clinical Division of Obstetrics \& Gynaecology, University of Leicester, University Rd, Leicester LE1 7RH, UK \\ ${ }^{2}$ Molecular and Cell Biology, University of Leicester, University Rd, Leicester LE1 7RH, UK \\ ${ }^{3}$ Department of Obstetrics and Gynaecology, Sidra Medical and Research Center, PO Box 26999, Doha, Qatar
}

*Correspondence: Justin C. Konje, Department of Obstetrics and Gynaecology, Sidra Medicine, Doha and Wellness Women's Research Center, HMC, Doha, Qatar, E-mail: jck4@le.ac.uk or jkonje@sidra.org

Received: November 30, 2018; Accepted: March 20, 2019; Published: March 25, 2019

\begin{abstract}
Preterm birth (PTB) affects $9.6 \%$ of pregnancies worldwide and is associated with a very high perinatal mortality that depends on the gestational age at delivery. As a result, PTB has a significant health and financial impact on health systems, families and societies. Its aetiology is not fully understood, but in most cases it is multifactorial, with several maternal, paternal, and epidemiological factors associated with increased risk. Other factors include parental ethnicity, maternal age and body mass index, socioeconomic status, and where the families live. This review examines the influence of ethnicity as an individual risk factor for PTB. It also explores its influence on the epidemiology of PTB and demonstrates that data on certain ethnicities are lacking, despite the fact that these ethnic clusters are within the very 'high-risk groups' that are adequately represented in some Western societies.
\end{abstract}

Keywords: Preterm birth, Ethnicity, Epidemiology, Ethnic epidemiology

\section{Introduction}

The world is becoming more cosmopolitan with fluctuation in its populations and the mixing of ethnic groups. In the UK, immigration has progressively increased in the last two decades [1], with correspondingly more ethnically diverse communities [2]. A look at the ethnic makeup of Leicester in 2011, for example, showed that the Caucasian population was just marginally the most dominant ethnic group (Figure 1), making the city one of the 'most ethnically diverse' in the region and the whole country [3]. Such diversity can be challenging to practicing physicians as there is a wide variety in the pattern of diseases amongst ethnic groups.

Chart of the distribution of ethnic groups in Leicester in 2011 [4]. Chart created by the Leicester City Council based on results from the Office for National Statistics and National Statistics Agency (Crown copyright).

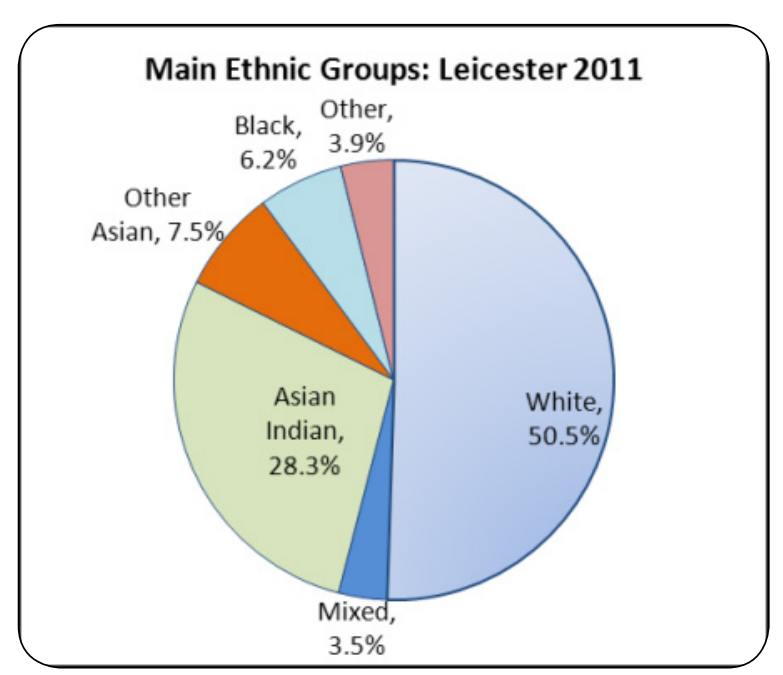

Figure 1: The distribution of different ethnic groups in Leicester. 
It is therefore essential to continue to investigate and understand the impact of such population changes on disease incidence and prevalence especially in obstetrics, where immigration has significantly increased birth rates [5]. In this review, we examine the impact of ethnicity on preterm birth.

Childbirth before 37 completed weeks of gestation is defined as preterm birth (PTB) [6] and affects $9.6 \%$ of all births worldwide [6] and 7.6\% of all births in the UK [7]. Worldwide, PTB is responsible for $75 \%$ of all perinatal deaths and more than half of these births are associated with long-term morbidities [8] and mortalities [9]. Surviving premature babies have multiple cardiovascular, respiratory and nervous system disorders, with both multiple short- and long-term recurring health needs [10]. As a result, premature infants require repeated hospitalisation, with the risk of acquiring late-onset nosocomial infections in addition to other health problems [11]. This is costly; in well-resourced societies (e.g. USA and UK) it is estimated that billions of dollars/ pounds are spent annually on the provision of care to premature babies $[12,13]$. The highest costs are applied to the treatment of very preterm infants; in the USA for example premature and low-birth-weight babies represent half of infant admissions [14]. In fact, late preterm infants also use far more health service resources than term neonates, and it is only by 3 years that costs of healthcare for these equilibrate [15].

This economic impact on the healthcare system starts well before parturition. Approximately, one-third of all antenatal hospital admissions are due to 'threatened preterm labour (PTL)/PTB' $[16,17]$. Of these, $50-80 \%$ go to full term without any further antenatal admissions [18]. It is universally acknowledged that the implementation of proper diagnostics, protocols and management plans of women at 'high-risk' of PTB, can save unnecessary admissions without jeopardising the patients' welfare [19-21]. The main problems associated with PTB thus start with repeated 'unnecessary' maternal antenatal admissions, which cause stress to the mother and could be a contributing factor to PTB [22]. Furthermore, following birth, repeated hospitalisations of the preterm infant which can be for months and years, add significantly to the financial, social, and psychological costs on the healthcare system and families.

Identifying women at high risk of PTB and instituting measures to treat PTL as early as possible would be a logical approach to reduce the impact of PTB [8].
There are many different classifications of PTB. These are determined by the rationale of the classification, e.g. clinical presentation, gestational age at birth, aetiology or the proposed mechanism of labour [8,23-26].

In 2012 a classification based on five components of the clinical phenotype of (a) maternal and (b) fetal conditions present before presentation for delivery, (c) placental pathological conditions, (d) signs of initiation of parturition, and (e) the pathway to delivery was proposed [27]. However, this is a retrospective approach which provides only a better understanding of the causes of preterm birth and improvements in surveillance across populations. As a result, this classification has not been found to be very helpful.

Another classification, based on retrospective findings and applicable before 28 weeks, uses factor analysis for the comparison of maternal socio-demographic characteristics, clinical presentation, and the histological and microbiological patterns of the placenta [28]. Based on these findings two types of PTB thus exist: (a) one due to established intrauterine inflammation (e.g. pPROM, placental abruption, cervical insufficiency) and (b) the other where there is dysfunctional placentation (e.g. preeclampsia and intrauterine growth restriction).

There are different upper limits of gestational age in various classifications of PTB not only in the literature but also in hospitals in the same country [29]. This leads to varied epidemiology and outcomes when the same data are examined. A similar global discrepancy exists with regards to the age of viability [30]; while the age of fetal viability in the UK is 24 weeks [31], in the USA attempts at fetal resuscitation before that gestational age and as early as 20 weeks [32-34] has occurred. As a result, comparisons of miscarriages, PTB and term births becomes difficult, especially as what is considered a PTB in one country (e.g. at 36 weeks and 6 days in the UK), in another country is considered term birth. We consider the WHO definition (delivery before 37 completed weeks of gestation) as being the most appropriate for epidemiological studies and one that should be used for ethnicity studies into PTB rates.

A literature search was conducted through Pubmed, CINAHL, Embase, and Google Scholar. The search terms used were ethnicity, preterm birth and risk factors for preterm birth, including publications since 1980 and published only in English. An additional search was conducted for relevant governmental reports, 
consensuses, national statistics and non-clinical articles. The publications were from online journals and articles, and most of them were retrospective population and cohort studies.

\section{Ethnicity}

The most extensive multi-ethnic epidemiological studies have been from the USA, where there is a great ethnic diversity due to the economic migration. The data from the USA, thus, offers the standard for global epidemiological investigations from which comparisons can be made.

A clear difference in the risk of PTB among different ethnic groups exists in the USA, where women of African descent are at the highest risk of preterm or very early preterm birth, followed by Caucasians, Hispanics, and East Asians [8,35]. The incidence of PTB in Chinese women has always been lower than all other ethnicities (3.1 - 5.8\%) [36], despite an increase from the low of 3.1\% in 2005 to a peak of $7.1 \%$ in 2010 [37]. Native Americans [American Indians/Alaskan Natives (Al/ANs)], in one study, were found to have a 1.34 times higher risk of PTB than Caucasians [38], whilst a different study, which examined the birth records in North Dakota (USA) from 1978 to 1992, showed that Native Americans were at a $45 \%$ higher risk for PTB than Caucasians [39]. In all cases, the neonatal outcome in very preterm babies was not influenced by maternal ethnicity [40].

\section{Maternal age}

Extremes of age ( $<18$ and $>35$ years of age) are known to be independent risk factors for PTB $[41,42]$. Combining the risk of maternal age with ethnicity (African-American, Caucasian, and Hispanics), showed that all teenage mothers ( $<18$ years) were at a higher risk of PTB, especially if multiparous [43]. However, the risk of extreme prematurity among mothers of African-American descent was lower in the teenage group than in the 25 - to 29-year-olds. On the other hand, in teenage Caucasians, the risk of extreme (less than 28 gestational weeks) and severe prematurity (from 28 to 31 gestational weeks) was found to be higher than moderate prematurity (32 to 33 gestational weeks). Primigravidae older than 35 years of age (40-49 years) were equally found to be at a high risk for PTB among all three ethnic groups, while multiparous Africans and Hispanics had a higher risk for moderate and severe prematurity [43]. Native American mothers in the extreme age groups (i.e., teenagers and over 36 years) and (even if the fathers were teenagers) were at a higher risk of a PTB in comparison to Caucasians of the same age or gender [39]. Therefore, there are some ethnic differences in the risk of PTB when extreme age at the time of conception is taken into account.

\section{Inter-pregnancy intervals and pPROM}

Short inter-pregnancy intervals (IPI) ( $<12$ months) increase the risk of subsequent PTB [44], whilst increasing the IPI up to 18 to 23 months reduces the risk of PTB by $4 \%$ in Caucasians and $8 \%$ in AfricanAmericans in the subsequent pregnancy [45]. The effect of IPI becomes more complicated when multiple risk factors are combined. For example, women who have experienced PPROM in previous pregnancies are at high risk of experiencing it again [46], and the risk tends to be even more exaggerated the shorter the IPI. This is slightly higher in African-Americans compared to Caucasians [47], but this may be related to the fact that AfricanAmericans are more susceptible to PPROM than other ethnicities [48,49].

\section{BMI and multiple pregnancies}

Mothers with extremes of body mass index (BMI) (either underweight or obese) are known to be at high risk of PTB [50,51]. During pregnancy, high (more than $0.52 \mathrm{~kg} /$ wk) and low (less than $0.27 \mathrm{~kg} / \mathrm{wk}$ ) weight gain in AfricanAmericans who had previously had a PTB, increased the risk of having another PTB [52]. This association was not found with Caucasians, Hispanics or Asians and in fact, Asians with low weight gain and a previous PTB were not found to be at higher risk of recurrence [52]. Similarly, multiple gestations are another independent risk factor for PTB [53], which may be either spontaneous, secondary to uterine over-distension or iatrogenic because of gestational complications. The rate of twin pregnancies has increased in the last 30 years by $76 \%$ in the wellresourced countries [54] and by $101 \%$ in the USA [55], i.e., 2-4\% of all births [54]. By contrast, twin pregnancy rates in Southeast China remained consistently low (0.60 - 0.70\%) from 1993 to 2005 [56]. A possible reason for this increase is the assisted reproduction treatments (ART), which have increased during the same time period. The rate of multiple pregnancies (especially the dizygotic twins) [57] has increased due to ART, and these pregnancies are at a higher risk of very preterm delivery [58]. Dizygotic pregnancies have an overall world-wide incidence of 13/1000 live births; these are more common in sub-Saharan countries (23/1000 live births) and less common in Asia (6/1000 live births) [59]. Interestingly, this variation in the incidence of multiple pregnancies will have an impact on PTB rates. In Southern Brazil $[60,61]$ in the state of Rio Grande do Sul, where $80 \%$ of the 
population is Caucasian [62], the twin pregnancy rate has been constantly higher in comparison with the rest of the country. The rate in that state was $1.8 \%$, between 1990 to 1994, whilst in a district of its town Cândido Godói (CG) it was $10 \%$ giving the town a rate of approximately $2 \%$. From 1994 to 2006, the twin rate in CG remained at an average of about $2 \%$ while in the whole country it was less than $1 \%$. A similar geographical and ethnic isolate was found in Southwest Nigeria, where twinning rates reach 46.5/1000 deliveries [63]. The reason for this huge twinning rate, in the absence of ART, may be due to genetic rather than other epidemiological factors. The rate of PTB in multiple gestations varies in western countries [64], possibly due to different practices in patient management, but it remains around 60\% [54]. The rate in twin pregnancies is $50 \%$ and rises to $90 \%$ in triplet pregnancies [65]. Advanced maternal age increases the chances of a dichorionic twin pregnancy, either spontaneously or due to assisted conception treatment, but it seems to have a positive effect on PTB rates [66].

While among women with twin pregnancies below the age of 30, African-Americans are at higher risk of PTB, followed by Caucasians and then Hispanics, this changes dramatically with advancing age, where the risk increases in all three groups being highest in Caucasians [55].

\section{Genetics}

There are some epidemiological factors that have suggested a genetic component of PTB, independent of ethnicity. Women who are born premature themselves or if their siblings were, are at risk of having a PTB [67]. Moreover, in women who previously had a PTB, the risk persists and keeps increasing with every subsequent pregnancy [68]. Considering that an ethnic pattern is also implicated in the risk of PTB, it can be concluded that inheritance is involved. What these genetic factors are, is the subject of fierce research. What has been established is that polymorphisms encoding pro-inflammatory cytokines are associated with PTB [69-72]. Indeed, variations exist among different ethnicities (AfricanAmerican and Caucasian) in the amniotic fluid cytokine concentrations [73], for example whereas interleukin (IL)- 1 is dominant in African-American mothers, IL- 8 is higher in Caucasians. Another difference is in response to infectious agents, where fetal membranes from Caucasian pregnancies react by producing more tumour necrosis factor-a (TNF-a) and IL-10, while AfricanAmerican pregnancies produce mainly IL-1, whereas IL-8 levels were similar in both groups $[74,75]$.
In Chinese women, a polymorphism in the SEPS1G105A gene seems to increase the risk of PTB, through an increase in the pro-inflammatory cytokines IL-1 $\beta$, IL-6 and TNF-a [76]. Likewise, Japanese women with polymorphisms and haplotypes in the IL1-A genes are at a high risk of PTB [70]. Selected TNF/LTA haplotypes have also been found to increase the risk of PTB equally in African-Americans and Caucasians [69]. In women from Northern India, it has been suggested that their risk of PTB increases with polymorphisms in the Cytochrome P4501B1 (CYP1B1) gene (a homozygous variant of $\mathrm{CYP} 1 \mathrm{~B} 1 * 2$ and heterozygous variant of $\mathrm{CYP} 1 \mathrm{~B} 1 * 3$ and CYP1B1*7 genes) [77]. In addition, several studies have correlated polymorphisms in the CYP1A1 and GSTT1 genes with an increased risk of PTB [78-81], but here the results differ radically among differing ethnicities. For example, studies in a Chinese population showed that mutations in these two genes are associated with an increased risk of PTB either individually [79] or with passive smoking [78], whilst earlier multi-ethnic studies $[80,81]$ found a similar correlation between these genetic mutations and the risk of PTB and low birth weight (LBW) in African-American women, but not in Caucasians. However, such risks were present only in smokers and in those exposed to toxins, such as benzene. In conclusion, CYP1A1 and GSTT1 mutations seem to be associated with PTB in Chinese women, whereas in African-Americans they have a selective effect and there appears to be no influence in Caucasians.

The effect of antenatal corticosteroid therapy has also been shown to be influenced by maternal ethnicity [82]. Antenatal corticosteroid therapy is often used in women at high risk of PTB to accelerate lung maturity in the fetus of women who have gone into preterm labour. Corticosteroid metabolism is controlled by enzymes of the cytochrome p450 (CYP) family $[83,84]$ and such expression is influenced by ethnicity $[85,86]$ with most African-Americans expressing CYP proteins, whilst only $10 \%$ of Caucasians do. As a result, this leads to faster activity and shorter bioavailability of corticosteroids in African-Americans. Depression increases the risk of PTB in both African-Americans and Caucasians [87], and despite stress being another independent risk factor for PTB [88], it seems this factor does not preferentially increase PTB risk in any specific ethnic group [89].

\section{Effect of neighbourhood, psyche, and intentions}

Neighbourhoods of lower socioeconomic status (SES) form an independent risk factor for PTB [90], with the 'neighbourhood factor', in the form of deprived areas, 
leading to an increase in risk in both African-Americans and Caucasians [91]. The incidence of PTB in AfricanAmericans who live in Hispanic neighbourhoods was noted to decrease, possibly due to amelioration in psychosocial or lifestyle factors [92]. This observation was confirmed in other studies that showed that a maternal 'positive sense of life-satisfaction' [93] and acquiring a 'healthy life-approach' with adequate healthcare provision [94], reduced the risk of PTB in low-income African-Americans. Not surprisingly, there was an evident decline in the risk noted in the 1990s in African-American women following macroeconomic improvements [95].

Neighborhood ethnic density compared among seven different ethnic groups (non-Hispanic white, non-Hispanic black, Spanish Caribbean, Central American and Mexican, South American Hispanic, East Asian, and South Asian), in New York, over an 8-year period (1995-2003), proved exclusively that non-Hispanic blacks were at a higher risk for PTB [96]. A more detailed analysis of the effect of ethnic density among African-Americans, Caribbean, and US-born non-Hispanic African-Americans, in the aforementioned population and the risk of PTB, showed that the risk was higher in US-born non-Hispanic AfricanAmericans than in immigrants [97]. Similar findings were shown in studies on Arab-Americans who lived in Michigan [98,99]. Not only were women of Arab ancestry at lower risk of PTB than Caucasian women, but USborn Arabs (Arab-Americans) were at a higher risk than immigrant Arabs. These findings were thus attributed to 'environmental factors'.

Examining the "neighbourhood impact" on a bigger scale, the risk of PTB has been noted to increase in Hispanic (Mexican) immigrants in the USA [100] and in Chinese women acquiring a Western lifestyle [36]. Another reason why generalisation leads to inaccuracy, and that social factors are a strong element in the aetiology of PTB, is the fact that the risk of PTB is higher in non-Hispanic AfricanAmerican than in non-Hispanic African immigrants [97]. It is evident that despite the inter-ethnic differences in the risk of PTB in low SES, the main reason for the increase is related to maternal weathering, (a weakening of the maternal health state with the advancement of age), which is accelerated with social disparities [101-104].

One more habit that increases the risk of PTB is unhealthy nutrition and specifically low intake of omega-3 fatty acids [105]. An omega-6/omega-3 fatty acid ratio in maternal plasma that is greater than 15 in Caucasian women was associated with a higher risk of PTB at the time of delivery, but a similar ratio does not form a risk for African-American women [106]. This suggests that nutrition either before or during pregnancy has a direct impact on PTB, but whether this effect has an ethnic basis has not been fully established.

Unintended pregnancies carry a higher risk of PTB and can be associated with concomitant SES that makes the risk even higher [107]. The risk of having an unintended pregnancy is determined mainly by SES factors rather than ethnicity, even though some difference has been noted. For example, in California, unmarried Hispanics are at a lower risk than unmarried Middle-Eastern or Europeans [108]. An assessment of the risk of PTB with an unplanned pregnancy in the same city, among different ethnicities, put Caucasians and immigrant Hispanics at higher risk than US-born Hispanics and African-Americans [108]. Even after an adjustment of the SES factor, immigrant Hispanics remained at a higher risk of PTB than all other groups within the study.

Finally, a more complex attempt to find an association between bacterial vaginosis (BV), lower SES and ethnicity, as a risk for PTB between Caucasian and African-American women, showed no significant ethnic difference [109].

\section{Paternal contribution}

Paternal ethnicity from several studies on bi-racial couples has been shown to contribute to the risk of PTB $[110,111]$. However, since most of the studies [112] were in the USA, the only ethnicities studied were AfricanAmericans and Caucasians. In a bi-racial couple where the father was African-American the risk of PTB was higher than if the mother was. Nevertheless, bi-racial couples present a lower PTB risk profile than couples where both parents are African-Americans [112]. A comparable study, but with noted limitations, related to Middle-Eastern ethnicity suggested that the risk of PTB is higher in couples where the mother is of Middle-Eastern descent, while the father is not, in comparison to a couple where both parents are of Middle-Eastern descent [113]. These data suggest that there are more contributing factors to the risk of PTB other than the maternal genotype, but that the paternal genotype and hence the fetal genotypes may indeed be involved.

\section{The impact of gestational age on PTB epidemiological studies}

An important factor underlying the incidence and prevalence of PTB and influencing epidemiological studies, whether ethnicity is a factor or not, is the 
definition of PTB. The WHO defines "term pregnancy" as 37 completed weeks of gestation. A large national study in the USA showed that neonates born at 37 weeks of gestation were at a higher risk of mortality in comparison to those born at 38 and 39 weeks (2.3/1000 live-born infants vs. 1.7 and 1.4/1000, respectively), with a plateau between 39 to 40 weeks [114]. Interestingly, no ethnic variation was noted among low-risk African-Americans and Caucasians. An even larger study examining over 46 million births concluded that the risk of neonatal mortality was high at 37 and, to some extent, at 38 weeks of gestation [115]; with ethnic variation taken into the analysis, African-Americans were found to be at higher risk at 37 weeks (2.2/1000 live-born infants), followed by Caucasians (1.6/1000) and then Hispanics (1.5/1000). At 38 weeks the risk fell considerably, in African-Americans 1.2/1000, Hispanics 1.0/1000 and Caucasians 0.9/1000. These data suggest that the timing of studies in which ethnicity has a role to play also needs to be carefully considered.

\section{Discussion}

The epidemiology of PTB remains highly contentious. The wide spectrum of risks and aetiological factors, the endless possibilities of perplexed scenarios where several contributory factors can be present make this very complex. As the possible number of risk factors increases and become more complex, so does the variability in the global incidence of PTB [116-120].

As mentioned earlier, the world is becoming pluralistic, a change that offers an opportunity to study the different ethnicities and their possible interrelation with certain clinical conditions and risks. As a principle, any possible correlation discovered by these epidemiological findings can help thousands, if not millions, all over the world. In the case of PTB, it helps to identify 'high-risk women' and thus enable early counselling and intervention to improve the outcome.

Most comprehensive studies on the epidemiology of PTB were performed in the USA and understandably examined the impact of ethnic differences, with the main ethnicities being US born African-Americans and Caucasians, and to an extent Hispanics. Independently, when women of the same ethnicity were exposed to different social and environmental circumstances (e.g., migration), the risks for PTB changed. Moreover, a discrepancy in the risk of PTB was also found among women who are of the same ethnic origin, (e.g., AfricanAmericans, Caribbean and African-immigrants [97]) due to variations in their ethnic densities. It was easy to conclude that, (a) ethnicity sometimes can be a malleable risk factor, and (b) certain ethnicities can be subdivided into subgroups with individual risk factors. A further exploration of the ethnic subdivision is provided in other studies comparing rates in sub-ethnic groups [121]. The first example is a comparison of the rate of PTB in subSaharan Africa (12.3\%) to that in the Caribbean (11.2\%). The second example is a similar comparison between the rates in the Caucasus and in Central Asia (i.e. regions of origin for 'Caucasians' where historically there has been a reduced chance of ethnic diversity) where the rates are 9.2\% and differ from the $8.6 \%$ rate found in the 'Developed Regions'. It is evident that despite the presence of similar ethnic features, in both of the examples above, there are discrepancies in the incidences that should be considered.

These findings suggest that ethnicity, its subdivisions, and their interaction with various factors, especially the environment, have an impact on the epidemiology of PTB. This is more applicable in geographical areas with large and diverse populations.

India is the country with the highest number of PTBs globally (23.6\%) [121] while China, the most populous country in the world, is second but its PTB rates are only one-third of India (7.8\%) (Table 1). Furthermore, India, Pakistan, and Bangladesh are in the top 10 countries with PTBs forming one-third of the global preterm deliveries (31.4\%) [121]. In fact, six out of the top ten countries are in the Asian sub-continent. Their populations combined form half the citizens of the globe (3.2 billion) and the numbers of PTB represent $46 \%$ (6.88 million) of the total PTBs worldwide. More interestingly, Pakistan and Indonesia (Table 1) are the only non-African countries with high PTB rates (15.8\% and 15.5\%, respectively) [121]. An argument can be made that these countries have limited resources and therefore unfavourable environmental and social factors. However, the USA, a more resourced country, is ranked sixth in the global table, while in other regions such as Northern Africa and Latin America the rates are $7.3 \%$ and $8.4 \%$, placing them 4th and 5th in the table. Therefore, such anecdotal arguments about the lack of resources and a poor environment being the main contributory factors in PTB risk are inadequate. Still, we conclude from all this that despite consistent research and studies on different epidemiological factors and ethnic discrepancies involved in PTB, very little attention has been given to the Asian continent, in general, and the Indian sub-continent in particular. 
Table 1: The top ten countries with the highest numbers of PTB in 2010.

\begin{tabular}{l|l|l|l|l}
\hline & $\begin{array}{c}\text { Rank for number } \\
\text { of } \\
\text { preterm births }\end{array}$ & $\begin{array}{c}\text { Number of } \\
\text { preterm births } \\
\text { (\% of global total) }\end{array}$ & $\begin{array}{c}\text { Preterm birth } \\
\text { rate } \\
\text { (\% of live births) }\end{array}$ & $\begin{array}{c}\text { Number of live } \\
\text { births } \\
\text { (\% of global total) }\end{array}$ \\
\hline India & 1 & $3519118(23.6 \%)$ & $13.0 \%$ & $27200000(20.1 \%)$ \\
\hline China & 2 & $1172259(7.8 \%)$ & $7.1 \%$ & $16600000(12.3 \%)$ \\
\hline Nigeria & 3 & $773597(5.2 \%)$ & $12.2 \%$ & $63332251(4.7 \%)$ \\
\hline Pakistan & 4 & $748142(5.0 \%)$ & $15.8 \%$ & $4741460(3.5 \%)$ \\
\hline Indonesia & 5 & $675744(4.5 \%)$ & $15.5 \%$ & $4371818(3.2 \%)$ \\
\hline USA & 6 & $517443(3.5 \%)$ & $12.0 \%$ & $4300620(3.2 \%)$ \\
\hline Bangladesh & 7 & $424144(2.3 \%)$ & $14.0 \%$ & $3037652(2.3 \%)$ \\
\hline Philippines & 8 & $348871(2.3 \%)$ & $14.9 \%$ & $2344154(1.7 \%)$ \\
\hline $\begin{array}{l}\text { Democratic Republic } \\
\text { of Congo }\end{array}$ & 9 & $341421(2.3 \%)$ & $11.9 \%$ & $2872606(2.1 \%)$ \\
\hline Brazil & 10 & $279256(1.9 \%)$ & $9.2 \%$ & $3022823(2.2 \%)$ \\
\hline Total & & 8.8 million (59\%) & & 74.8 million (55\%) \\
\hline
\end{tabular}

In the USA, citizens of Indian/South Asian descent represent only $1 \%$ of the entire population [122], so their ethnicity is insufficiently reflected in epidemiological studies. In the UK, on the other hand, where South Asians (from India, Pakistan and Bangladesh) form 5.3\% of the country's population [2] and in cities (such as Leicester) with a big Asian community (28.3\%), such epidemiological studies have yet to be undertaken.

\section{Conclusion}

The epidemiology of PTB is rather complex, especially when different coexisting risk factors are taken into account. Ethnicity plays a role with obvious differences amongst various ethnic groups. A more thorough examination of ethnicity will help in unveiling other potential associated risk factors and the extent of these risks in PTB. A better knowledge of ethnical epidemiology not only helps in identifying women who are at 'high risk', but will also allow the offer of the appropriate management. Certain ethnicities have not been studied, despite the facts that they are very 'highrisk groups' and are also adequately represented in some Western societies. It is about time that these studies are undertaken.

The WHO has conveniently highlighted the incidence and consequences of PTB and offers some broadline suggestions for its management $[6,123]$, however, various management approaches seem to only minimally influence outcome at the unit level with specific clinical guidelines that only deal with specific complications. It is thus recommended that the $\mathrm{WHO}$ and national health authorities encourage a closer examination of the epidemiology of PTB and investigate how this can influence intervention and management of PTB, either in the form of new preventive methods or in early detection of clinical complications, but remembering that ethnicity could be a confounding variable.

\section{Key points}

1. Preterm birth is a common obstetric complication with significant health and financial impacts on the patients and health system.

2. Ethnicity is known to be a risk factor for preterm birth.

3. Many risk factors for preterm birth are affected by ethnicity, like maternal age, BMI, paternal ethnicity, and socio-economic status.

4. Ethnic epidemiology helps in the early management of women who are at 'high risk'.

5. Countries and cities with multi-ethnic populations could offer further answers by comparing the different ethnicities and their influence on the risk of PTB.

\section{Declarations}

The authors have nothing to declare.

\section{References}

1. Cangiano A. The impact of migration on UK population growth. Migration Observatory. https:// migrationobservatory.ox.ac.uk/resources/briefings/ the-impact-of-migration-on-uk-population-growth/ 
2. Ethnicity and national identity in England and Wales. https://www.ons.gov.uk/ peoplepopulationandcommunity I culturalidentity/ethnicity/articles/ ethnicityandnationalidentityinenglandandwales/ 2012-12-11

3. Census 2011: Leicester "most ethnically diverse" in region. $B B C$ News. https://www.bbc.com/news/ukengland-leicestershire-20678326. Published 2012.

4. Ethnic origin of residents: Leicester, 2001 - 2011. Leicester City Council; 2012.

5. Births in England and Wales, 2012. http://www.ons. gov.uk/ons/dcp171778_317196.pdf.

6. Beck S, Wojdyla D, Say L, et al. The worldwide incidence of preterm birth: A systematic review of maternal mortality and morbidity. Bull World Health Organ. 2010;88(1):31-38. Doi: https://doi.org/10.2471/ BLT.08.062554

7. Preterm births, England and Wales. Office of National Statistics. 2005.

8. Goldenberg RL, Culhane JF, lams JD, et al. Epidemiology and causes of preterm birth. The Lancet. 2008;371(9606):75-84. Doi: https://doi.org/10.1016/ S0140-6736(08)60074-4

9. Lawn JE, Wilczynska-Ketende $\mathrm{K}$, Cousens $\mathrm{SN}$. Estimating the causes of 4 million neonatal deaths in the year 2000. Int J Epidemiol. 2006;35(3):706-718. Doi: https://doi.org/10.1093/ije/dyl043

10. Ward RM, Beachy JC. Neonatal complications following preterm birth. Int J Gynaecol Obstet. 2003;110:8-16. Doi: https://doi.org/10.1046/j.14710528.2003.00012.x

11. Benjamin DK, Stoll BJ. Infection in late preterm infants. Clin Perinatol. 2006;33(4):871-882. Doi: https://doi. org/10.1016/j.clp.2006.09.005

12. Institute of Medicine (US) Committee on understanding premature birth and assuring healthy outcomes. Preterm birth: Causes, consequences, and prevention. (Behrman RE, Butler AS, eds.). Washington (DC): National Academies Press (US); 2007. http:// www.ncbi.nlm.nih.gov/books/NBK11362/.

13. Ng SM, Weindling AM. The impact of networks on clinical trials in the United Kingdom. Trials. 2009;10(1):100. Doi: https://doi.org/10.1186/17456215-10-100

14. Russell RB, Green NS, Steiner CA, et al. Cost of hospitalization for preterm and low birth weight infants in the United States. Pediatrics. 2007;120(1):e1- e9. Doi: https://doi.org/10.1542/peds.2006-2386

15. Bérard A, Le Tiec M, De Vera MA. Study of the costs and morbidities of late-preterm birth. Arch Dis Child Fetal Neonatal Ed. 2012;97(5):F329-F334. Doi: https:// doi.org/10.1136/fetalneonatal-2011-300969

16. Bennett TA, Kotelchuck M, Cox CE, et al, Nadeau DA. Pregnancy-associated hospitalizations in the United States in 1991 and 1992: A comprehensive view of maternal morbidity. Am J Obstet Gynecol. 1998;178(2):346-354. https://www.ncbi.nlm.nih.gov/ pubmed/9500498

17. Bacak SJ, Callaghan WM, Dietz PM, et al. Pregnancyassociated hospitalizations in the United States, 1999-2000. Am J Obstet Gynecol. 2005;192(2):592-597. Doi: https://doi.org/10.1016/j.ajog.2004.10.638

18. Murphy DJ. Epidemiology and environmental factors in preterm labour. Best Pract Res Clin Obstet Gynaecol. 2007;21(5):773-789. Doi: https://doi.org/10.1016/j. bpobgyn.2007.03.001

19. Lucovnik M, Chambliss LR, Garfield RE. Costs of unnecessary admissions and treatments for "threatened preterm labor." Am J Obstet Gynecol. 2013;209(3):217.e1-217.e3. Doi: https://doi. org/10.1016/j.ajog.2013.06.046

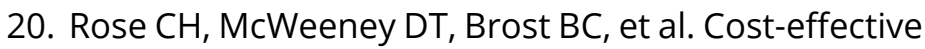
standardization of preterm labor evaluation. $\mathrm{Am}$ J Obstet Gynecol. 2010;203(3):250.e1-250.e5. Doi: https://doi.org/10.1016/j.ajog.2010.06.037

21. Giles W, Bisits A, Knox M, et al. The effect of fetal fibronectin testing on admissions to a tertiary maternal-fetal medicine unit and cost savings. Am J Obstet Gynecol. 2000;182(2):439-442. Doi: https://doi. org/10.1016/S0002-9378(00)70236-5

22. Wadhwa PD, Entringer S, Buss $C$, et al. The contribution of maternal stress to preterm birth: Issues and considerations. Clin Perinatol. 2011;38(3):351-384. Doi: https://doi.org/10.1016/j.clp.2011.06.007

23. Moutquin J-M. Classification and heterogeneity of preterm birth. BJOG: Int J Gynecol Obstet. 2003;110:30-33. Doi: https://doi.org/10.1046/j.14710528.2003.00021.x

24. Shapiro-Mendoza CK, Lackritz EM. Epidemiology of late and moderate preterm birth. Semin Fetal Neonatal Med. 2012;17(3):120-125. Doi: https://doi. org/10.1016/j.siny.2012.01.007

25. Raju TNK. Epidemiology of late preterm (near-term) births. Clin Perinatol. 2006;33(4):751-763. Doi: https:// doi.org/10.1016/j.clp.2006.09.009 
26. Klebanoff MA, Keim SA. Epidemiology: The changing face of preterm birth. Clin Perinatol. 2011;38(3):339350. Doi: https://doi.org/10.1016/j.clp.2011.06.006

27. Villar J, Papageorghiou AT, Knight HE, et al. The preterm birth syndrome: a prototype phenotypic classification. Am J Obstet Gynecol. 2012;206(2):119123. Doi: https://doi.org/10.1016/j.ajog.2011.10.866

28. McElrath TF, Hecht JL, Dammann O, et al. Pregnancy disorders that lead to delivery before the 28th week of gestation: An epidemiologic approach to classification. Am J Epidemiol. 2008;168(9):980-989. Doi: https://doi.org/10.1093/aje/kwn202

29. Vahratian A, Buekens P, Alexander GR. State-specific trends in preterm delivery: Are rates really declining among non-Hispanic African Americans across the United States? Matern Child Health J. 2006;10(1):27-32. Doi: https://doi.org/10.1007/s10995-005-0032-4

30. Pignotti M. The definition of humanviability:Ahistorical perspective. Acta Paediatr. 2010;99(1):33-36. Doi: https://doi.org/10.1111/j.1651-2227.2009.01524.x

31. Royal College of Obstetricians and Gynaecologists. The management of early pregnancy loss. Green-Top Guideline No 25. 2006.

32. Seri I, Evans J. Limits of viability: Definition of the gray zone. J Perinatol. 2008;28(S1):S4-S8. Doi: https://doi. org/10.1038/jp.2008.42

33. Kaempf JW. Medical staff guidelines for periviability pregnancy counseling and medical treatment of extremely premature infants. Pediatrics. 2006;117(1):22-29. Doi: https://doi.org/10.1542/ peds.2004-2547

34. Goldenberg RL, McClure EM. The epidemiology of preterm birth. In: Preterm birth. WileyBlackwell; 2010:22-38. Doi: https://doi. org/10.1002/9781444317619.ch4

35. MacDorman MF. Race and ethnic disparities in fetal mortality, preterm birth, and infant mortality in the United States: An overview. Semin Perinatol. 2011;35(4):200-208. Doi: https://doi.org/10.1053/j. semperi.2011.02.017

36. Newnham JP, Sahota DS, Zhang CY, et al. Preterm birth rates in Chinese women in China, Hong Kong and Australia - The price of Westernisation: Preterm birth in Chinese women. Aust N Z J Obstet Gynaecol. 2011;51(5):426-431. Doi: https://doi.org/10.1111/ j.1479-828X.2011.01327.x

37. World Health Organization. International Statistical Classification of Diseases and Related Health
Problems: 10th Revision ICD-10. Geneva: World Health Organization; 2016. https://www.who.int/ classifications/icd/ICD10Volume2_en_2010.pdf

38. Hwang $M$, Shrestha A, Yazzie S, et al. Preterm birth amongAmerican Indian/AlaskannativesinWashington and Montana: Comparison with non-Hispanic Whites. Matern Child Health J. 2013;17(10):1908-1912. Doi: https://doi.org/10.1007/s10995-012-1215-4

39. Abel EL, Kruger M, Burd L. Effects of maternal and paternal age on caucasian and native American preterm births and birth weights. Am J Perinatol. 2002;19(01):049-054. Doi: https://doi. org/10.1055/s-2002-20173

40. Petrova A, Mehta R, Anwar M, et al. Impact of race and ethnicity on the outcome of preterm infants below 32 weeks gestation. J Perinatol. 2003;23(5):404-408. Doi: https://doi.org/10.1038/sj.jp.7210934

41. Mcintyre SH, Newburn-Cook CV, O'Brien Bet al. Effect of older maternal age on the risk of spontaneous preterm labor: A population-based study. Health Care Women Int. 2009;30(8):670-689. Doi: https://doi. org/10.1080/07399330802596473

42. da Silva AAM, Simoes VMF, Barbieri MA, et al. Young maternal age and preterm birth. Paediatr Perinat Epidemiol. 2003;17(4):332-339. Doi: https://doi. org/10.1046/j.1365-3016.2003.00515.x

43. Schempf AH, Branum AM, Lukacs SL, et al. Maternal age and parity-associated risks of preterm birth: Differences by race/ethnicity. Paediatr Perinat Epidemiol. 2007;21(1):34-43. Doi: https://doi. org/10.1111/j.1365-3016.2007.00785.x

44. DeFranco EA, Stamilio DM, Boslaugh SE, et al. A short interpregnancy interval is a risk factor for preterm birth and its recurrence. Am J Obstet Gynecol. 2007;197(3):264.e1-264.e6. Doi: https://doi. org/10.1016/j.ajog.2007.06.042

45. Hogue CJ, Menon R, Dunlop AL, et al. Racial disparities in preterm birth rates and short inter-pregnancy interval: An overview. Acta Obstet Gynecol Scand 2011;90(12):1317-1324. Doi: https://doi.org/10.1111/ j.1600-0412.2011.01081.x

46. Asrat T, Lewis DF, Garite TJ, et al. Rate of recurrence of preterm premature rupture of membranes in consecutive pregnancies. Am J Obstet Gynecol. 1991;165(4):1111-1115. Doi: https://doi. org/10.1016/0002-9378(91)90481-6

47. Getahun D, Strickland D, Ananth CV, et al. Recurrence of preterm premature rupture of membranes in relation to interval between pregnancies. Am J Obstet 
Gynecol. 2010;202(6):570.e1-570.e6. Doi: https://doi. org/10.1016/j.ajog.2009.12.010

48. Goldenberg RL, Cliver SP, Mulvihill FX, et al. Medical, psychosocial, and behavioral risk factors do not explain the increased risk for low birth weight among black women. Am J Obstet Gynecol. 1996;175(5):1317-1324. Doi: https://doi.org/10.1016/S0002-9378(96)70048-0

49. Savitz DA, Blackmore CA, Thorp JM. Epidemiologic characteristics of preterm delivery: Etiologic heterogeneity. Am J Obstet Gynecol. 1991;164(2):467471. Doi: https://doi.org/10.1016/S00029378(11)80001-3

50. Han Z, Mulla S, Beyene J, et al. Maternal underweight and the risk of preterm birth and low birth weight: A systematic review and meta-analyses. Int J Epidemiol. 2011;40(1):65-101. Doi: https://doi.org/10.1093/ije/ dyq195

51. Torloni MR, Betrán AP, Daher $S$, et al. Maternal $\mathrm{BMI}$ and preterm birth: A systematic review of the literature with meta-analysis. J Matern Fetal Neonatal Med. 2009;22(11):957-970. Doi: https://doi. org/10.3109/14767050903042561

52. Stotland $N E$, Caughey $A B$, Lahiff $M$, et al. Weight gain and spontaneous preterm birth: The role of race or ethnicity and previous preterm birth. Obstet Gynecol. 2006;108(6):1448-1455. Doi: https://doi. org/10.1097/01.AOG.0000247175.63481.5f

53. Gardner M, Goldenberg R, Cliver S, et al. The origin and outcome of preterm twin pregnancies. Obstet Gynecol. 1995;85(4):553-557. Doi: https://doi. org/10.1016/0029-7844(94)00455-M

54. Ananth CV, Chauhan SP. Epidemiology of twinning in developed countries. Semin Perinatol. 2012;36(3):156-161. Doi: https://doi.org/10.1053/j. semperi.2012.02.001

55. Chauhan SP, Scardo JA, Hayes E, et al. Twins: Prevalence, problems, and preterm births. Am J Obstet Gynecol. 2010;203(4):305-315. Doi: https://doi. org/10.1016/j.ajog.2010.04.031

56. Lu X, Zhang J, Liu Y, et al. Epidemiology of twin births in Southeast China: 1993-2005. Twin Res Hum Genet. 2013;16(2):608-613. Doi: https://doi.org/10.1017/ thg.2013.7

57. Allen VM, Wilson RD, Cheung A, et al. Pregnancy outcomes after assisted reproductive technology. J Obstet Gynaecol Can. 2006;28(3):220-233. Doi: https:// doi.org/10.1016/S1701-2163(16)32112-0

58. Moini A, Shiva M, Arabipoor A, et al. Obstetric and neonatal outcomes of twin pregnancies conceived by assisted reproductive technology compared with twin pregnancies conceived spontaneously: A prospective follow-up study. Eur J Obstet Gynecol Reprod Biol. 2012;165(1):29-32. Doi: https://doi.org/10.1016/j. ejogrb.2012.07.008

59. Hoekstra C, Zhao ZZ, Lambalk CB, et al. Dizygotic twinning. Hum Reprod Update. 2008;14(1):37-47. Doi: https://doi.org/10.1093/humupd/dmm036

60. Tagliani-Ribeiro A, Oliveira $M$, Sassi AK, et al. Twin town in South Brazil: A Nazi's experiment or a genetic founder effect? Harpending $\mathrm{H}$, ed. PLoS ONE. 2011;6(6):e20328. Doi: https://doi.org/10.1371/ journal.pone.0020328

61. Matte U, Le Roux MG, Bénichou B, et al. Study on possible increase in twinning rate at a small village in South Brazil. Acta Genet Med Gemellol (Roma). 1996;45(04):431-437. Doi: https://doi.org/10.1017/ S0001566000000829

62. Race and ethnicity in Brazil. 2006. http://en.wikipedia. org/wiki/Race_and_ethnicity_in_Brazil\#cite_notePNAD_2005-101.

63. Bakare A, Akinboro A, Azeez M. Frequency of twinning in Southwest Nigeria. Indian J Hum Genet. 2008;14(2):41-47. Doi: https://doi.org/10.4103/09716866.44104

64. Blondel B, Macfarlane A, Gissler M, et al. General obstetrics: Preterm birth and multiple pregnancy in European countries participating in the PERISTAT project. BJOG: Int J Gynaecol Obstet. 2006;113(5):528535. Doi: https://doi.org/10.1111/j.14710528.2006.00923.x

65. Alexander GR, Kogan M, Martin J, et al. What are the fetal growth patterns of singletons, twins, and triplets in the United States? Clin Obstet Gynecol. 1998;41(1):115-125. Doi: https://doi. org/10.1097/00003081-199803000-00017

66. Lisonkova S, Joseph KS, Bell R, et al. Effect of advanced maternal age on perinatal outcomes in twins: The impact of chorionicity. Ann Epidemiol. 2013;23(7):428-434. Doi: https://doi.org/10.1016/j. annepidem.2013.05.005

67. Bhattacharya S, Amalraj Raja E, Ruiz Mirazo E, et al. Inherited predisposition to spontaneous preterm delivery. Obstet Gynecol. 2010;115(6):1125-1133. Doi: https://doi.org/10.1097/AOG.0b013e3181dffcdb

68. Orsi NM, Gopichandran N, Simpson NAB. Genetics of preterm labour. Best Pract Res Clin Obstet Gynaecol. 2007;21(5):757-772. Doi: https://doi.org/10.1016/j. 
bpobgyn.2007.03.020

69. Engel SAM, Erichsen HC, Savitz DA, et al. Risk of spontaneous preterm birth is associated with common proinflammatory cytokine polymorphisms. Epidemiology. 2005;16(4):469-477. Doi: https://doi. org/10.1097/01.ede.0000164539.09250.31

70. Sata F, Toya S, Yamada H, et al. Proinflammatory cytokine polymorphisms and the risk of preterm birth and low birth weight in a Japanese population. Mol Hum Reprod. 2009;15(2):121-130. Doi: https://doi. org/10.1093/molehr/gan078

71. Yılmaz Y, Verdi $H$, Taneri A, et al. Maternal-fetal proinflammatory cytokine gene polymorphism and preterm birth. DNA Cell Biol. 2012;31(1):92-97. Doi: https://doi.org/10.1089/dna.2010.1169

72. Pereyra S, Velazquez T, Bertoni B, et al. Rapid multiplex high resolution melting method to analyze inflammatory related SNPs in preterm birth. BMC Res Notes. 2012;5(1):69. Doi: https://doi. org/10.1186/1756-0500-5-69

73. Menon R, Fortunato SJ, Velez Edwards DR, et al. Association of genetic variants, ethnicity and preterm birth with amniotic fluid cytokine concentrations. Ann Hum Genet. 2010;74(2):165-183. Doi: https://doi. org/10.1111/j.1469-1809.2010.00562.x

74. Menon R, Merialdi M, Lombardi SJ, et al. Differences in the placental membrane cytokine response: $A$ possible explanation for the racial disparity in preterm birth. Am J Reprod Immunol. 2006;56(2):112-118. Doi: https://doi.org/10.1111/j.1600-0897.2006.00394.x

75. Fortunato SJ, Lombardi SJ, Menon R. Racial disparity in membrane response to infectious stimuli: a possible explanation for observed differences in the incidence of prematurity. Community Award Paper. Am J Obstet Gynecol. 2004;190(6):1557-1562; discussion 15621563. Doi: https://doi.org/10.1016/j.ajog.2004.03.053

76. Wang Y, Yang X, Zheng Y, et al. The SEPS1 G-105A polymorphism is associated with risk of spontaneous preterm birth in a Chinese population. Catapano A, ed. PLOS ONE. 2013;8(6):e65657. Doi: https://doi. org/10.1371/journal.pone.0065657

77. Mustafa M, Sharma T, Banerjee BD, et al. Genetic polymorphisms in Cytochrome P 4501B1 and susceptibility to idiopathic preterm labor in North Indian population. Clin Biochem. 2013;46(18):18121815. Doi: $\quad$ https://doi.org/10.1016/j. clinbiochem.2013.07.019

78. Luo Y-J, Wen X-Z, Ding P, et al. Interaction between maternal passive smoking during pregnancy and Cur Op Gyn Obs, 2(1): 180-192 (2019)
CYP1A1 and GSTs polymorphisms on spontaneous preterm delivery. Szecsi PB, ed. PLOS ONE. 2012;7(11):e49155. Doi: https://doi.org/10.1371/ journal.pone.0049155

79. Zhang $\mathrm{M}$, Cheng $\mathrm{Y}$, Dong $\mathrm{S}$, et al. Polymorphisms of GSTM1, GSTT1 and CYP1A1 genes in mothers and neonates related to susceptibility to preterm delivery. Wei Sheng Yan Jiu. 2008;37(2):155-158.

80. Wang X. Maternal cigarette smoking, metabolic gene polymorphism, and infant birth weight. JAMA. 2002;287(2):195-202. Doi: https://doi.org/10.1001/ jama.287.2.195

81. Wang X. Genetic susceptibility to benzene and shortened gestation: Evidence of gene-environment interaction. Am J Epidemiol. 2000;152(8):693-700. Doi: https://doi.org/10.1093/aje/152.8.693

82. Haas DM, Sischy AC, McCullough W, et al. Maternal ethnicity influences on neonatal respiratory outcomes after antenatal corticosteroid use for anticipated preterm delivery. J Matern Fetal Neonatal Med. 2011;24(3):516-520. Doi: https://doi.org/10.3109 /14767058.2010.506228

83. Thummel KE, Wilkinson GR. In vitro and in vivo drug interactions involving human CYP3A. Annu Rev Pharmacol Toxicol. 1998;38(1):389-430. Doi: https:// doi.org/10.1146/annurev.pharmtox.38.1.389

84. Cholerton S, Daly AK, Idle JR. The role of individual human cytochromes $\mathrm{P} 450$ in drug metabolism and clinical response. Trends Pharmacol Sci. 1992;13:434-439. Doi: https://doi.org/10.1016/01656147(92)90140-2

85. Kuehl P, Zhang J, Lin $Y$, et al. Sequence diversity in CYP3A promoters and characterization of the genetic basis of polymorphic CYP3A5 expression. Nat Genet. 2001;27(4):383-391. Doi: https://doi. org/10.1038/86882

86. Hustert $E$, Haberl M, Burk $O$, et al. The genetic determinants of the CYP3A5 polymorphism. Pharmacogenetics. 2001;11(9):773-779. Doi: https:// doi.org/10.1097/00008571-200112000-00005

87. Gavin AR, Chae DH, Mustillo S, et al. Prepregnancy depressive mood and preterm birth in Black and White women: Findings from the CARDIA Study. J Womens Health. 2009;18(6):803-811. Doi: https://doi. org/10.1089/jwh.2008.0984

88. Dole N, Savitz D, Hertz-Picciotto I, et al. Maternal stress and preterm birth. Am J Epidemiol. 2003;157(1):14-24. Doi: https://doi.org/10.1093/aje/kwf176 
89. Lu MC, Chen B. Racial and ethnic disparities in preterm birth: The role of stressful life events. Am J Obstet Gynecol. 2004;191(3):691-699. Doi: https://doi. org/10.1016/j.ajog.2004.04.018

90. Messer LC, Vinikoor LC, Laraia BA, et al. Socioeconomic domains and associations with preterm birth. Soc Sci Med. 2008;67(8):1247-1257. Doi: https://doi. org/10.1016/j.socscimed.2008.06.009

91. O'Campo P, Burke JG, Culhane J, et al. Neighborhood deprivation and preterm birth among non-Hispanic black and white women in eight geographic areas in the United States. Am J Epidemiol. 2008;167(2):155163. Doi: https://doi.org/10.1093/aje/kwm277

92. Mason SM, Kaufman JS, Daniels JL, et al. Black preterm birth risk in nonblack neighborhoods: effects of Hispanic, Asian, and non-Hispanic white ethnic densities. Ann Epidemiol. 2011;21(8):631-638. Doi: https://doi.org/10.1016/j.annepidem.2011.04.008

93. Orr ST, Orr CA, James SA, et al. Life satisfaction and preterm birth among urban Black women: findings from the Baltimore preterm birth study. Ann Epidemiol. 2012;22(11):759-763. Doi: https://doi.org/10.1016/j. annepidem.2012.09.002

94. Orr ST, Reiter JP, James SA, et al. Maternal health prior to pregnancy and preterm birth among urban, low income Black women in Baltimore: the Baltimore Preterm Birth Study. Ethn Dis. 2012;22(1):85-89. https://www.ncbi.nlm.nih.gov/pubmed/22774314

95. Schempf AH, Decker SL. Decline in the United States Black preterm/low birth weight rate in the 1990s: can the economic boom explain it? Ann Epidemiol. 2010;20(11):862-867. Doi: https://doi.org/10.1016/j. annepidem.2010.07.100

96. Mason SM, Kaufman JS, Daniels JL, et al. Neighborhood ethnic density and preterm birth across seven ethnic groups in New York City. Health Place. 2011;17(1):280-288. Doi: https://doi.org/10.1016/j. healthplace.2010.11.006

97. Mason SM, Kaufman JS, Emch ME, et al. Ethnic density and preterm birth in African, Caribbean, and US-Born non-Hispanic Black populations in New York City. Am J Epidemiol. 2010;172(7):800-808. Doi: https://doi. org/10.1093/aje/kwq209

98. El-Sayed AM, Galea S. Explaining the low risk of preterm birth among Arab Americans in the United States: An analysis of 617451 births. Pediatrics. 2009;123(3):e438-e445. Doi: https://doi.org/10.1542/ peds.2008-1634

99. El Reda DK, Grigorescu V, Posner SF, et al. Lower Cur Op Gyn Obs, 2(1): 180-192 (2019) rates of preterm birth in women of Arab Ancestry: An epidemiologic paradox-Michigan, 1993-2002. Matern Child Health J. 2007;11(6):622-627. Doi: https://doi. org/10.1007/s10995-007-0199-y

100.Guendelman S, English PB. Effect of United States residence on birth outcomes among Mexican immigrants: An exploratory study. Am J Epidemiol. 1995;142(Supplement 9):S30-S38. Doi: https://doi. org/10.1093/aje/142.Supplement_9.S30

101.Burris HH, CollinsJW. Race and preterm birth: The case for epigenetic inquiry. Ethn Dis. 2010;20(3):296-299. https://www.ncbi.nlm.nih.gov/pubmed/20828105

102.Love C, David RJ, Rankin KM, et al. Exploring weathering: Effects of lifelong economic environment and maternal age on low birth weight, small for gestational age, and preterm birth in AfricanAmerican and White women. Am J Epidemiol. 2010;172(2):127-134. Doi: https://doi.org/10.1093/ aje/kwq109

103.Collins JW, Rankin KM, Hedstrom AB. Exploring weathering: The relation of age to low birth weight among first generation and established United States-born Mexican-American women. Matern Child Health J. 2012;16(5):967-972. Doi: https://doi. org/10.1007/s10995-011-0827-4

104. Holzman C, Eyster J, Kleyn M, et al. Maternal weathering and risk of preterm delivery. Am J Public Health. 2009;99(10):1864-1871. Doi: https://doi. org/10.2105/AJPH.2008.151589

105. Olsen SF, Secher NJ, Tabor A, et al. Randomised clinical trials of fish oil supplementation in high risk pregnancies. BJOG: Int J Gynaecol Obstet. 2000;107(3):382-395. Doi: https://doi. org/10.1111/j.1471-0528.2000.tb13235.x

106.Dunlop AL, Taylor RN, Tangpricha V, et al. Maternal micronutrient status and preterm versus term birth for Black and White US women. Reprod Sci. 2012;19(9):939-948. Doi: https://doi. org/10.1177/1933719112438442

107.Shah PS, Balkhair T, Ohlsson A, et al. Intention to become pregnant and low birth weight and preterm birth: A systematic review. Matern Child Health J. 2011;15(2):205-216. Doi: https://doi.org/10.1007/ s10995-009-0546-2

108.Cubbin C, Braveman PA, Marchi KS, et al. Socioeconomic and racial/ethnic disparities in unintended pregnancy among postpartum women in California. Matern Child Health J. 2002;6(4):237-246. Doi: https://doi.org/10.1023/A:1021158016268 
109. Meis PJ, Goldenberg RL, Mercer BM, et al. Preterm prediction study: Is socioeconomic status a risk factor for bacterial vaginosis in Black or in White women. Am J Perinatol. 2000;17(01):041-046. Doi: https://doi. org/10.1055/s-2000-7292

110.Palomar L, DeFranco EA, Lee KA, et al. Paternal race is a risk factor for preterm birth. Am J Obstet Gynecol. 2007;197(2):152.e1-152.e7. Doi: https://doi. org/10.1016/j.ajog.2007.03.035

111.Simhan HN, Krohn MA. Paternal race and preterm birth. Am J Obstet Gynecol. 2008;198(6):644.e1-644.e6. Doi: https://doi.org/10.1016/j.ajog.2007.11.046

112.Srinivasjois RM, Shah S, Shah PS. Biracial couples and adverse birth outcomes: A systematic review and meta-analyses. Acta Obstet Gynecol Scand. 2012;91(10):1134-1146. Doi: https://doi.org/10.1111/ j.1600-0412.2012.01501.x

113.El-Sayed AM, Galea S. Interethnic mating and risk for preterm birth among Arab-American mothers: Evidence from the Arab-American birth outcomes study. J Immigr Minor Health. 2011;13(3):445-452. Doi: https://doi.org/10.1007/s10903-010-9341-9

114.Zhang $\mathrm{X}$, Kramer MS. Variations in mortality and morbidity by gestational age among infants born at term. J Pediatr. 2009;154(3):358-362.e1. Doi: https:// doi.org/10.1016/j.jpeds.2008.09.013

115. Reddy UM, Bettegowda VR, Dias T, et al. Term pregnancy: A period of heterogeneous risk for infant mortality. Obstet Gynecol. 2011;117(6):1279-1287. Doi: https://doi.org/10.1097/AOG.0b013e3182179e28

116. Morin M, Arnaud C, Germany L, et al. Preterm birth: Evolution 1994 to 2006. Gynecol Obstet Fertil. 2012;40(12):746-752. Doi: https://doi.org/10.1016/j. gyobfe.2012.05.007

117.VanderWeele TJ, Lantos JD, Lauderdale DS. Rising preterm birth rates, 1989-2004: Changing demographics or changing obstetric practice? Soc Sci Med. 2012;74(2):196-201. Doi: https://doi. org/10.1016/j.socscimed.2011.10.031
118.Loftin RW, Habli M, Snyder CC, et al. Late preterm birth. Rev Obstet Gynecol. 2010;3(1):10-19. Doi: https:/ www.ncbi.nlm.nih.gov/pmc/articles/PMC286317/

119.Tracy S, Tracy M, Dean J, et al. Spontaneous preterm birth of live born infants in women at low risk in Australia over 10 years: A population-based study. BJOG: Int J Gynaecol Obstet. 2007;114(6):731-735. Doi: https://doi.org/10.1111/j.1471-0528.2007.01323.x

120.Cheong JL, Doyle LW. Increasing rates of prematurity and epidemiology of late preterm birth: Epidemiology of late preterm birth. J Paediatr Child Health. 2012;48(9):784-788. Doi: https://doi.org/10.1111/ j.1440-1754.2012.02536.x

121.BlencoweH,CousensS, Oestergaard MZ, etal. National, regional, and worldwide estimates of preterm birth rates in the year 2010 with time trends since 1990 for selected countries: A systematic analysis and implications. The Lancet. 2012;379(9832):2162-2172. Doi: https://doi.org/10.1016/S0140-6736(12)60820-4

122.Race reporting for the Asian population by selected categories: 2010. US Census Bureau. http://factfinder2.census.gov/faces/tableservices/ jsf/pages/productview.xhtml?pid=DEC_10_SF1_ QTP8\&prodType=table.

123.WHO. Preterm birth. https://www.who.int/newsroom/fact-sheets/detail/preterm-birth. Published 2012.

124.Migration and migrant population statistics. https:// ec.europa.eu/eurostat/statistics-explained/index. php?title=Migration_and_migrant_population_ statistics

Copyright: ( $)$ Bachkangi et al. This is an Open Access article distributed under the terms of the Creative Commons Attribution License, which permits unrestricted use, distribution, and reproduction in any medium, provided the original work is properly cited. 